\title{
Associations between Urinary, Dietary, and Water Fluoride Concentrations among Children in Mexico and Canada
}

\author{
Rivka Green ${ }^{1}$, Christine Till ${ }^{1}$, Alejandra Cantoral ${ }^{2, *} \mathbb{0}$, Bruce Lanphear ${ }^{3}$, \\ E. Angeles Martinez-Mier ${ }^{4}{ }^{(}$, Pierre Ayotte ${ }^{5}$, Robert O. Wright ${ }^{6}$, Martha M. Tellez-Rojo ${ }^{7}$ and \\ Ashley J. Malin ${ }^{6}$ \\ 1 Department of Psychology, York University, Toronto, ON M3J 1P3, Canada; rrgreen@yorku.ca (R.G.); \\ ctill@yorku.ca (C.T.) \\ 2 Departamento de Salud, Universidad Iberoamericana, Ciudad de México 01219, Mexico \\ 3 Faculty of Health Sciences, Simon Fraser University, Vancouver, BC V5A 1S6, Canada; bpl3@sfu.ca \\ 4 School of Dentistry, Indiana University, Indianapolis, IN 46202, USA; esmartin@iu.edu \\ 5 Department of Social and Preventive Medicine, Laval University, Quebec City, QC G1V 0A6, Canada; \\ pierre.ayotte@inspq.qc.ca \\ 6 Environmental Medicine and Public Health, Icahn School of Medicine at Mount Sinai, \\ New York, NY 10029, USA; robert.wright@mssm.edu (R.O.W.); ashley.malin@mssm.edu (A.J.M.) \\ 7 School of Public Health, Instituto Nacional de Salud Pública, Cuernavaca 62100, Mexico; mmtellez@insp.mx \\ * Correspondence: alejandra.cantoral@insp.mx; Tel.: +52(55)-5950-4000
}

Received: 25 September 2020; Accepted: 30 October 2020; Published: 20 November 2020

\begin{abstract}
Fluoride, which may be toxic to the developing brain, is added to salt in Mexico and drinking water in Canada to prevent dental caries. We compared childhood urinary fluoride (CUF) concentrations in Mexico City and Canada to characterize patterns of fluoride exposure in these two populations. We also examined associations of CUF with dietary and water fluoride levels in Mexico City and Canada respectively. We included 561 children (ages 4-6; mean age 4.8 years) from the Programming Research in Obesity, Growth, Environment, and Social Stress (PROGRESS) cohort in Mexico City, and 645 children (ages 2-6; mean age 3.7 years) from the Maternal-Infant Research on Environmental Chemicals (MIREC) cohort in Canada. We applied Spearman correlations, T-tests, ANOVA or covariate-adjusted linear regression to examine associations of CUF (mg/L; adjusted for specific gravity) with demographics and dietary or water fluoride concentrations. We used Welch equivalence testing to compare means across cohorts. Mean (SD) CUF was equivalent $(t=4.26, p<0.001)$ in PROGRESS: $0.74(0.42)$ and fluoridated Canadian communities: $0.66(0.47)$, but lower in non-fluoridated Canadian communities: $0.42(0.31)(t=-6.37, p<0.001)$. Water fluoride concentrations were significantly associated with CUF after covariate adjustment for age and sex in MIREC ( $B=0.44,95 \%$ CI: $0.30,0.59, p<0.001)$. In contrast, daily food and beverage fluoride intake was not associated with CUF in PROGRESS $(p=0.82)$. We found that CUF levels are comparable among children in Mexico City and fluoridated Canadian communities, despite distinct sources of exposure. Community water fluoridation is a major source of fluoride exposure for Canadian children.
\end{abstract}

Keywords: urinary fluoride; childhood; Mexico; Canada

\section{Introduction}

Fluoride is often added to water, salt, or milk to prevent dental cavities [1]. Approximately $39 \%$ of Canadians and $73 \%$ of Americans on public water distribution systems have fluoride added to drinking water to achieve the optimal concentration of $0.7 \mathrm{mg} / \mathrm{L}$ for dental carries prevention $[2,3]$. 
In the United States (US), fluoridated water is the main source of fluoride exposure, accounting for approximately $60 \%$ of total daily fluoride intake among adults, and $42 \%$ of total daily fluoride intake among children under the age of 12 [4]. In Mexico, sodium fluoride or potassium fluoride are added to salt at $250 \pm 50 \mathrm{mg} / \mathrm{L}$ in regions where naturally occurring fluoride in water is less than $0.7 \mathrm{mg} / \mathrm{L}$, such as Mexico City [5]. Other sources of fluoride can include fluoridated dental products and supplements, certain dietary products that contain naturally occurring fluoride, such as green and black tea, and foods that are sprayed with fluoride-containing pesticides (i.e., grapes) [6,7].

Water fluoride concentrations are moderately to strongly correlated with urinary fluoride levels [8-10] and blood plasma levels [11,12]. Indeed, urinary fluoride levels typically approximate the concentration of fluoride found in tap water in adults $[9,13,14]$ and children $[15,16]$. In Mexico, salt fluoride intake patterns or contributions of salt fluoride to urinary fluoride levels are not well-established [17].

Fluoride may be a developmental neurotoxicant, even in populations exposed to "optimal" levels, especially for exposure in the prenatal period [18-23]. For example, cross-sectional studies have reported associations between higher water fluoride levels in Canada and an increased risk of ADHD symptoms and/or diagnosis in children and adolescents, but they did not find the same association with child urinary fluoride [18]. Similarly, most recent studies of cohorts exposed to optimally fluoridated levels have not found an association between fluoride exposure in childhood and adverse neurodevelopmental outcomes, such as diminished IQ scores and diagnosis of a learning disability or ADHD [15,22,24,25].

There are developmental factors that can influence urinary fluoride concentration in children. For example, fluoride excretion is lower in children relative to adults due to differences in absorption $[12,26]$; children younger than seven years retain approximately $55-61 \%$ of daily ingested fluoride compared with $36 \%$ in healthy adults [7,27]. Further, children younger than four years of age are more likely to swallow toothpaste due to an immature swallowing reflex, which contributes to increases in blood fluoride concentrations [28] and higher total daily fluoride intake [7]. Given widespread exposure to fluoride and the fine balance between optimal levels for oral health and excessive levels that may contribute to neurotoxicity, it is prudent to monitor fluoride intake and exposure levels among young children in North America.

Prior reports and Canadian studies that have characterized childhood urinary fluoride (CUF) have done so irrespective of fluoridation status [13,29]. For example, the Canadian Health Measures Survey (CHMS) reports a median creatinine-adjusted CUF level of $0.79 \mathrm{mg} / \mathrm{g}$ (unadjusted median CUF of $0.51 \mathrm{mg} / \mathrm{L}$ ) among children ages 3-5 years across Canada [29]. However, it is important to consider fluoridation status because urinary fluoride levels are approximately 1.5-2 times higher in fluoridated regions than non-fluoridated regions $[9,30,31]$. The purpose of this study was to compare child urinary fluoride (CUF) concentrations with dietary and water fluoride levels among children in Mexico City and Canada respectively. We also compared CUF levels by age, sex, and other demographic variables, within these two populations.

\section{Materials and Methods}

\subsection{Study Sample}

MIREC: The Maternal-Infant Research on Environmental Chemicals (MIREC) study is a large sample of pregnant women and children that were recruited from ten cities across Canada from 2008-2011 [32]. A subset of 2-6-year-old children from MIREC $(N=654)$ were recruited for the biomarker visit (MIREC-CD Plus) in childhood; of these, 645 (98.6\%) had CUF samples and 516 (78.9\%) had water fluoride measurements. A total of 450 (68.8\%) children had both a CUF sample and a water fluoride value, as well as complete covariate data. Ethics approval for MIREC was received from Health Canada's Research Ethics Board (Project \#: 2016-0015; approval date: 25 July 2016), York University 
Research Ethics Board, and Indiana University's Ethics Board. Informed consent was received from all participants.

PROGRESS: The Programming Research in Obesity, Growth, Environment, and Social Stress (PROGRESS) study is an ongoing NIH-funded, prospective birth cohort in Mexico City that involves 948 mother-offspring pairs who are followed from the 2nd trimester of pregnancy to the child's 10th birthday. Children are followed every six months following birth and every two years after 24 months of age. Multiple biological matrices (blood, plasma, hair, nails, urine, saliva) were collected longitudinally from mothers and their children. A more detailed description of the PROGRESS participant recruitment process is described elsewhere [33,34]. CUF and food/beverage fluoride values were analyzed among 551 and 561 participants, respectively. Participants in PROGRESS were eligible for inclusion in regression analyses if they had CUF measurements, complete covariate data, and food/beverage fluoride intake estimates $(n=539)$. Institutional Review Board approval for the PROGRESS study was granted by The Icahn School of Medicine at Mount Sinai (Project \#12-00751A; approved for continuation: 7 July 2020), Harvard School of Public Health, The National Institute of Public Health in Mexico (Project \#: CI-560-13072012; approval date: 13 July 2012), and the Brigham and Women's Hospital.

\subsection{Childhood Urinary Fluoride (CUF)}

We collected single urine samples under non-fasting conditions. For both the PROGRESS and MIREC cohorts, CUF concentrations were analyzed at the Oral Health Research Institute at Indiana University using a modification of the hexamethyldisoloxane (HMDS; Sigma Chemical Co.) microdiffusion procedure as modified by Martinez-Mier et al. (2011) [35,36]. A measured and recorded volume of each sample $(0.850 \mathrm{~mL})$ was dispensed into $15-\mathrm{cm}$ plastic Petri dishes (Falcon Fisher Scientific $\mathrm{Co}$.); a sodium hydroxide ( $\mathrm{NaOH}$, anhydrous; Sigma Chemical $\mathrm{Co}$.) trap solution was loaded onto the Petri dish lid and after adding sulfuric acid $\left(\mathrm{H}_{2} \mathrm{SO}_{4}\right.$; Sigma Chemical Co.) saturated with HMDS, each dish was tightly sealed. Fluoride was released by acid hydrolysis and trapped in the $\mathrm{NaOH}$ trap. The fluoride-containing trap was then removed and buffered to $\mathrm{pH} 5.2$ with perchloric acid $\left(\mathrm{HClO}_{4}\right.$; Sigma Chemical Co.). The resulting solution was adjusted to a final volume of $100 \mu \mathrm{L}$ with total ionic strength buffer (TISABII; Fisher Scientific Co.). Fluoride levels were determined by comparing the millivolt reading of each sample to standard curves, covering the range of the samples' values. Reference standard solutions were monitored daily by a quality assurance (QA) officer for stability.

To account for variations in urine dilution, CUF concentrations were standardized for specific gravity (SG) using the following equation [37]: $\mathrm{CUF}_{\mathrm{SG}}(\mathrm{mg} / \mathrm{L})=\mathrm{CUF}^{*}(\mathrm{SG} m-1) /(\mathrm{SG} i-1)$ where $\mathrm{CUF}_{\mathrm{SG}}$ $(\mathrm{mg} / \mathrm{L})$ is the SG standardized fluoride concentration, CUF $i$ is the observed fluoride concentration, SGi is the SG of the individual urine sample and SG $m$ is the median SG for the sample. Detailed methodology for urinary fluoride analysis and SG standardization are reported elsewhere [9].

\subsection{Dietary Fluoride Concentration (for the PROGRESS Cohort Only)}

Validated food frequency questionnaires (FFQ) were administered to mothers in PROGRESS to assess dietary patterns of their children over the previous week. FFQs included 101 foods/beverages grouped into 14 categories [38]. Total food and beverage fluoride intake (mcg/d) was calculated for 561 children using the estimates previously reported [17]. These estimates are based on analyses of fluoride content in 182 foods or beverages from Mexico City Markets and Supermarkets [17]. Foods were homogenized, and then frozen aliquots were shipped to the Indiana University School of Dentistry Oral Health Research Institute for fluoride analysis. Analysis of food and beverages was conducted using a modification of the hexamethyldisiloxane (HMDS: Sigma-Aldrich, Indianapolis, IN, USA) microdiffusion method as modified by Martinez-Mier et al. as described elsewhere [35]. 


\subsection{Measurement of Municipal Drinking Water Fluoride Levels (for the MIREC Cohort Only)}

We linked municipal public water reports with the first three digits of participants' postal codes, and water boundary regions were predetermined for each city. Water fluoride levels were only derived for those participants whose mothers reported drinking tap water as the primary drinking water source as a proxy for the type of water that children drink. For each participant, water fluoride values represented the average fluoride concentration measured by the water treatment plants over the six months prior to the urine sample.

Although naturally occurring water fluoride may exist in some of the non-fluoridated areas included in the study, the mean concentrations of fluoride in these regions is approximately $0.1 \mathrm{mg} / \mathrm{L}$. The present study defined a non-fluoridated site as having water fluoride levels (both adjusted and natural fluoride levels) as $<0.3 \mathrm{mg} / \mathrm{L}$. All fluoridated sites had corresponding water treatment plants that reported adding fluoride to the water supplies according to national drinking water guidelines [39], which includes a recommended range of $0.6 \mathrm{mg} / \mathrm{L}$ to $0.8 \mathrm{mg} / \mathrm{L}$ fluoride in the water.

\subsection{Covariates and Modifiers of Exposure Levels}

We selected variables that may modify fluoride metabolism and excretion based on literature review [26,40]. We examined the following covariates: age, sex, maternal education, body mass index (BMI; PROGRESS cohort), and child weight (MIREC cohort). Maternal education was defined as obtaining less than a secondary school education, a secondary school education, or greater than a secondary school education in the PROGRESS cohort, whereas in the MIREC cohort, given that the majority of the women were university educated, it was defined as university degree or higher versus college degree or lower. We also assessed race (white vs. non-white) in the MIREC cohort, but not for the PROGRESS cohort because of the limited heterogeneity in race and ethnicity.

\subsection{Statistical Analyses}

We used Spearman correlations to assess associations of $\mathrm{CUF}_{\mathrm{SG}}$ concentrations with age and BMI (in PROGRESS) or weight (in MIREC). We used t-tests or ANOVA to test mean differences in $\mathrm{CUF}_{\mathrm{SG}}$, food/beverage fluoride (for PROGRESS) or water fluoride (for MIREC), according to sex or maternal education, as well as race in MIREC. We used partial correlations to assess associations of food/beverage fluoride with age in PROGRESS, controlling for weight or total daily caloric intake. We applied two one-sided tests (TOST) Welch equivalence testing [41] to compare CUF $_{S G}$ means between PROGRESS and MIREC, which allows for skewed outcome data and does not assume equal variances between groups [42]. We conducted multiple linear regression to examine associations of $\mathrm{CUF}_{\mathrm{SG}}$ with food/beverage fluoride concentrations in PROGRESS and water fluoride concentrations in MIREC adjusted for covariates. We considered potential covariates a priori including age, sex, $\mathrm{BMI} /$ weight, race (MIREC only), and maternal education. However, we only retained covariates in the model that changed the B coefficient by $10 \%$ and/or had a $p<0.20$ when included in the model. The covariates that met criteria for inclusion in the regression models were age, sex and maternal education for PROGRESS, and age and sex for MIREC. In PROGRESS, we applied a $\log _{10}$-transformation of $\mathrm{CUF}_{\mathrm{SG}}$ and food/beverage fluoride intake prior to regression analysis to correct for skewness in $\mathrm{CUF}_{\mathrm{SG}}$ and food/beverage fluoride variables as well as to help to satisfy linear regression assumptions. In both cohorts, assumptions of linear regression were satisfied; no issues with multicollinearity were identified according to variable inflation factors, and no outliers were identified according to Cook's distance estimates. We also tested interactions of $\mathrm{CUF}_{\mathrm{SG}}{ }^{*}$ sex and $\mathrm{CUF}_{\mathrm{SG}}{ }^{*}$ age in both cohorts to assess whether the exposure-response profiles differed by sex or age. In MIREC, we tested the binary interaction of $\mathrm{CUF}_{\mathrm{SG}}{ }^{*}$ age (i.e., 2-3-year olds versus 4-6-year olds) to allow for more direct comparisons with PROGRESS, while in PROGRESS we included age as a continuous variable. These interaction terms were only retained in models for which they were significant. Two-tailed alphas of 0.05 for 
main effects and two-tailed alphas of 0.1 for interactions were the criteria for statistical significance in regression analyses.

\section{Results}

Demographic characteristics are presented in Table 1. The male to female ratio was balanced in both cohorts (i.e., approximately 50:50). The average age of children in the PROGRESS and MIREC cohorts was 4.80 and 3.66 years, respectively. The majority of mothers in MIREC (70.9\%) had an undergraduate degree or higher, while most mothers in PROGRESS (76.1\%) obtained a secondary school education or less. In MIREC, $87.4 \%$ of children were described as white by their mothers.

Table 1. Demographic characteristics of children with child urinary fluoride data.

\begin{tabular}{|c|c|c|}
\hline Demographic Variables & MIREC $(n=645)$ & PROGRESS $(n=551)$ \\
\hline \multicolumn{3}{|c|}{ Child Variables } \\
\hline Sex; N (\%) male & $326(50.5)$ & $282(51.2)$ \\
\hline Age (y); M (SD) & $3.66(0.87)$ & $4.80(0.56)$ \\
\hline Weight $(\mathrm{kg})$ or BMI $\left(\mathrm{kg} / \mathrm{m}^{2}\right)$ & $15.82(1.88) \mathrm{kg}$ & $15.71(1.71) \mathrm{kg} / \mathrm{m}^{2}$ \\
\hline \multirow{2}{*}{\multicolumn{3}{|c|}{ Maternal Variables }} \\
\hline & & \\
\hline & $\geq$ University Degree; 455 (70.9) & $<$ secondary school; 217 (39.4) \\
\hline & $\leq$ College Degree; 187 (29.1) & $\begin{array}{l}\text { secondary school; } 202(36.7) \\
\text { >secondary school; } 132(24)\end{array}$ \\
\hline $\operatorname{Race}(\mathrm{n}, \% \text { white })^{\mathrm{a}}$ & $564,87.9 \%$ & N/A \\
\hline
\end{tabular}

a data collected for Maternal-Infant Research on Environmental Chemicals (MIREC) study only. BMI = Body Mass Index.

Descriptive statistics for $\mathrm{CUF}_{\mathrm{SG}}$ as well as dietary fluoride in PROGRESS and water fluoride in MIREC are presented in Table 2. CUF $_{\text {SG }}$ was statistically equivalent $(t=4.26, p<0.001)$ in PROGRESS $(\mathrm{M}=0.74, \mathrm{SD}=0.42)$ and fluoridated Canadian communities $(\mathrm{M}=0.66, \mathrm{SD}=0.47)$, but lower in non-fluoridated Canadian communities $(M=0.42, S D=0.31)$, as compared to fluoridated Canadian

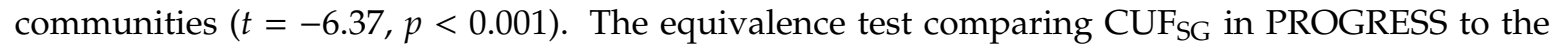
4-6-year olds specifically from fluoridated communities in MIREC was also significant $(t=-3.47$, $p<0.001)$.

Table 2. Descriptive statistics for childhood urinary fluoride (CUF), water fluoride, and dietary fluoride levels in the MIREC and PROGRESS cohorts.

\begin{tabular}{ccccc}
\hline Fluoride Matrix & $\mathbf{N}$ & Arithmetic Mean (SD) & Median (IQR) & 5th Percentile; 95th Percentile \\
\hline CUFSG (mg/L) & & & & \\
MIREC: Overall & $645^{\mathrm{a}}$ & $0.55(0.72)$ & $0.43(0.39)$ & $0.15 ; 1.35$ \\
$\quad$ Fluoridated & 219 & $0.66(0.47)^{*}$ & $0.53(0.43)$ & $0.22 ; 1.58$ \\
Non-fluoridated & 231 & $0.42(0.31)^{*}$ & $0.33(0.27)$ & $0.12 ; 1.14$ \\
MIREC (2-3-years) & & & & \\
$\quad$ Fluoridated & 140 & $0.50(0.39)^{*}$ & $0.50(0.39)$ & $0.22 ; 1.47$ \\
$\quad$ Non-fluoridated & 170 & $0.41(0.32)^{*}$ & $0.32(0.28)$ & $0.12 ; 1.13$ \\
MIREC (4-6 years) & & & & \\
$\quad$ Fluoridated & 79 & $0.79(0.56)^{*}$ & $0.64(0.59)$ & $0.25 ; 1.63$ \\
$\quad$ Non-fluoridated & 61 & $0.46(0.29)^{*}$ & $0.37(0.29)$ & $0.17 ; 1.15$ \\
PROGRESS (4-6 years) & 551 & $0.74(0.42)$ & $0.67(0.36)$ & $0.30 ; 1.32$ \\
Water Fluoride (mg/L) & & & & \\
MIREC: Overall & $516^{\mathrm{a}}$ & $0.35(0.25)$ & $0.20(0.49)$ & $0.035 ; 0.73$ \\
$\quad$ Fluoridated & 244 & $0.60(0.08)$ & $0.60(0.09)$ & $0.49 ; 0.74$ \\
$\quad$ Non-fluoridated & 272 & $0.12(0.06)$ & $0.11(0.17)$ & $0.04 ; 0.2$ \\
Dietary Fluoride (mcg/d) & & & & $321.27 ; 1261.15$ \\
$\quad$ PROGRESS & 561 & $693.89(311.67)$ & $630.64(372.73)$ &
\end{tabular}

Note. ${ }^{*} p<0.01$ for $t$-tests; ${ }^{a}$ sample sizes do not equal full sample size as not every child with a CUF measurement had a corresponding water fluoride measurement and vice versa. 


\subsection{Association between $C U F_{S G}$ and Covariates}

CUF $_{S G}$ was weakly and positively correlated with age in PROGRESS $(\rho=0.10, p=0.02)$ and MIREC $(\rho=0.23, p<0.001)$. In MIREC, $\mathrm{CUF}_{\mathrm{SG}}$ was similar in males $(\mathrm{M}=0.57, \mathrm{SD}=0.43)$ and females $(\mathrm{M}=0.53, \mathrm{SD}=0.42 ; t=1.14, p=0.25)$; no sex differences were observed in PROGRESS either $(t=0.04$, $p=0.97)$. We did not observe significant differences in $\mathrm{CUF}_{\mathrm{SG}}$ according to race in MIREC $(t=-1.42$, $p=0.16)$. CUFSG was not associated with maternal education in PROGRESS $(F=0.75, p=0.47)$ or MIREC $(t=-1.45, p=0.15)$. CUF SG was not correlated with BMI in PROGRESS $(\rho=-0.02, p=0.73)$ or child weight in MIREC $(\rho=0.10, p=0.20)$.

\subsection{Association between Fluoride Sources and Covariates}

In PROGRESS, dietary fluoride intake was weakly and positively associated with age $(r=0.17$, $p<0.001$ ) after adjusting for weight, such that older children consumed more fluoride from their daily diet than younger children. However, the association between dietary fluoride and age was attenuated after controlling for total daily calorie intake $(r=0.08, p=0.07)$. There were no significant differences in food/beverage fluoride intake according to maternal education $(F=1.62, p=0.20)$ or $\operatorname{sex}(t=1.1$, $p=0.27)$ and food/beverage fluoride intake was not associated with BMI $(\rho=-0.02, p=0.59)$.

In MIREC, as an artifact of the study design where sites began recruitment at different times, we observed that older children lived in areas with higher water fluoride concentrations; the correlation between water fluoride concentration and age was $(\rho=0.18, p<0.001)$. There were also significant differences in water fluoride concentration according to maternal education and race. Mothers who were less educated (i.e., college degree or lower) were more likely to live in cities with lower water fluoride concentrations $(\mathrm{M}=0.30 \mathrm{mg} / \mathrm{L}, \mathrm{SD}=0.24)$ than mothers with a higher education level (i.e., bachelor's degree or higher, $\mathrm{M}=0.36 \mathrm{mg} / \mathrm{L}, \mathrm{SD}=0.26, t=2.43, p=0.02$ ). Additionally, non-white mothers were somewhat more likely to live in cities with lower water fluoride levels $(M=0.30 \mathrm{mg} / \mathrm{L}$, $\mathrm{SD}=0.25)$ than white mothers $(\mathrm{M}=0.35 \mathrm{mg} / \mathrm{L}, \mathrm{SD}=0.25)$, but this difference did not reach significance $(t=-1.55, p=0.12)$. There were no significant differences in water fluoride concentrations by child sex $(t=0.15, p=0.88)$ and water fluoride concentration was not associated with child weight $(\rho=0.04$, $p=0.59$ ).

\subsection{CUF in Relation to Fluoride Sources}

Daily dietary fluoride intake was not associated with CUF $_{\mathrm{SG}}$ in PROGRESS (B $=-0.01,95 \%$, CI: $-0.06,0.05, p=0.82)$. In MIREC, water fluoride concentration was significantly associated with $\mathrm{CUF}_{\mathrm{SG}}$, after adjustment for age and sex $(\mathrm{B}=0.44,95 \%, \mathrm{CI}$ : $0.30,0.59, p<0.001)$; this association significantly interacted with sex $(p=0.07)$, but not age $(p=0.20)$. Specifically, water fluoride levels tended to be more strongly associated with $\mathrm{CUF}_{\mathrm{SG}}$ levels for males (B $=0.57,95 \% \mathrm{CI}$ : 0.37, 0.77), as compared to females ( $\mathrm{B}=0.31,95 \%$ CI: 0.10, 0.51; Figure 1$)$. 


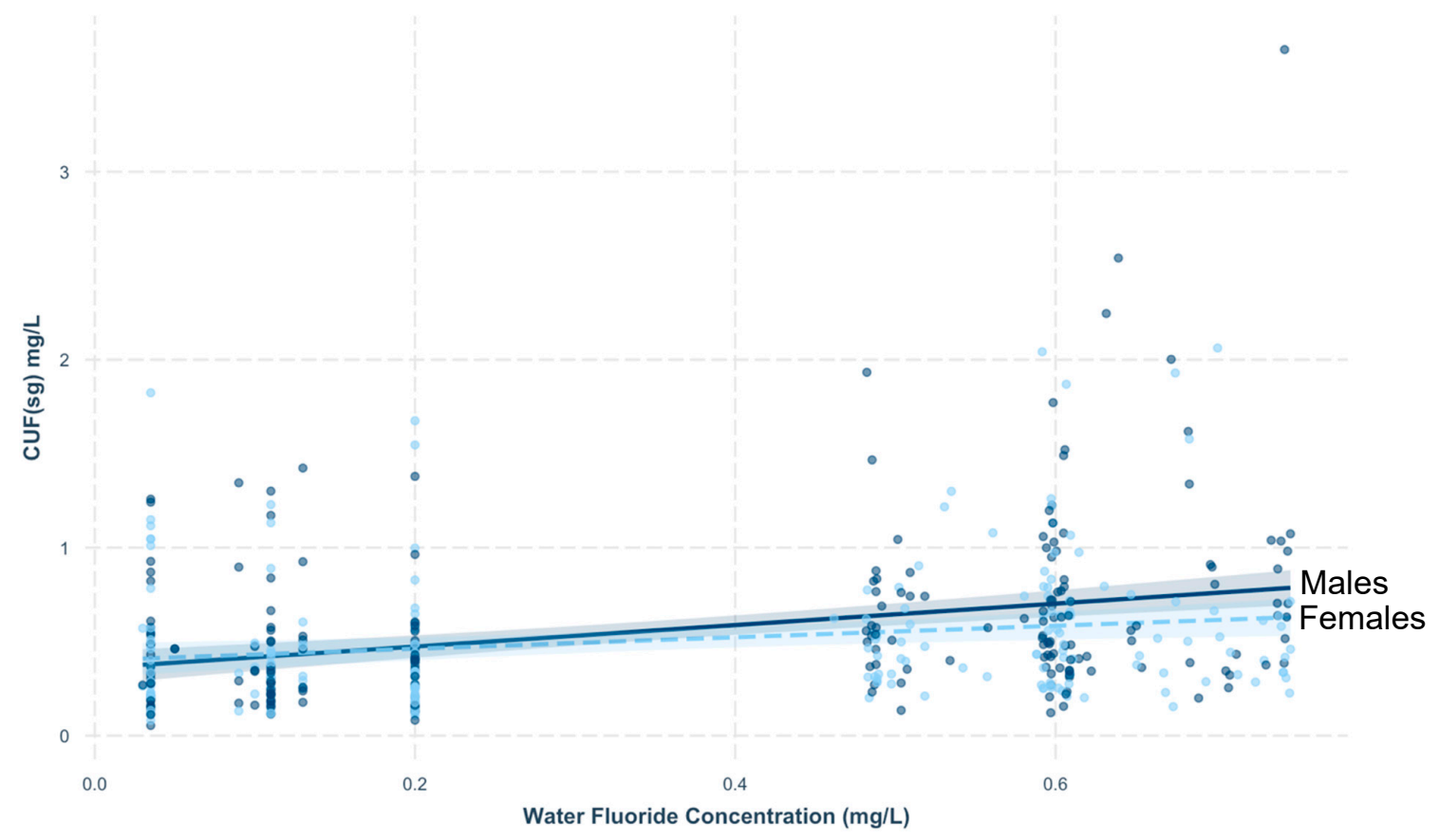

Figure 1. Associations of water fluoride concentration with $\mathrm{CUF}_{\mathrm{SG}}$ concentration in the MIREC cohort according to sex.

\section{Discussion}

We characterized child urinary fluoride $\left(\mathrm{CUF}_{\mathrm{SG}}\right)$ levels in two large prospective pregnancy and

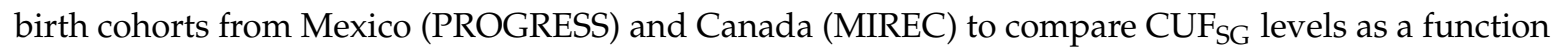
of fluoride sources and sociodemographic factors. Even though fluoride is added to salt in Mexico and water in some cities in Canada, we observed equivalent mean $\mathrm{CUF}_{\mathrm{SG}}$ concentrations among children in both cohorts. As expected, urinary fluoride levels were lower among children who lived in non-fluoridated $(M=0.42 \mathrm{mg} / \mathrm{L}, S D=0.31)$ than in fluoridated communities $(M=0.66 \mathrm{mg} / \mathrm{L}, S D=0.47$, Table 2).

Our findings are consistent with past biomonitoring studies conducted in children showing that levels of urinary fluoride are approximately 1.5 to 2 times higher in fluoridated regions than in non-fluoridated regions [9,31]. However, another study in Brazil [43] did not find meaningful differences in $\mathrm{CUF}_{\mathrm{SG}}$ patterns in relation to water fluoride levels among children ages 2-7-year olds. Still, all of the children in that study were exposed to water fluoride levels higher than $0.5 \mathrm{mg} / \mathrm{L}$ and fluoride retention has been shown to plateau at higher total daily fluoride intake levels [7].

We observed similar patterns of fluoride exposure by demographic factors in the two cohorts. In both PROGRESS and MIREC, CUF levels tended to increase with age. Interestingly, in PROGRESS we found that older children tended to consume more fluoride from their daily diet than younger children, even after controlling for weight; although, this association was partially due to higher caloric intake among older children. In MIREC, due to an artifact of study design, water fluoride was slightly correlated with age such that older children tended to live in regions with higher water fluoride concentrations. Thus, fluoride exposure or intake from community fluoridation (i.e., salt in Mexico and water in Canada) may partially account for differences in biomarker fluoride levels among children according to age. Older children are also more likely to use fluoridated toothpaste than 2-3-year-old children [28].

In MIREC, CUF and water fluoride concentrations did not differ according to sex. Consistently, in PROGRESS we did not observe differences in CUF or dietary fluoride intake by child's sex. We also did not find meaningful associations between CUF or dietary/water fluoride with BMI (in PROGRESS), 
weight (in MIREC), maternal education or race (in MIREC), although most ( $87 \%$ ) of the MIREC sample was white.

Dietary fluoride intake was not associated with CUF in the PROGRESS cohort. The FFQ utilized to estimate dietary fluoride intake did not, however, directly measure salt added to food after preparation. Given that salt fluoridation is widespread in Mexico [44], it is possible that our measure of salt intake was imprecise. Future studies employing more objective measures of dietary and salt fluoride intake should be conducted to more rigorously characterize contributions of dietary fluoride intake to CUF in Mexico.

In the MIREC cohort, we found that children exposed to higher water fluoride concentrations had significantly higher CUF concentrations, especially boys. Specifically, for each $1 \mathrm{mg} / \mathrm{L}$ increase in water fluoride concentration in Canada, CUF increased by $0.44 \mathrm{mg} / \mathrm{L}$ among all children; CUF increased by $0.57 \mathrm{mg} / \mathrm{L}$ among boys. This finding suggests that there may be metabolic differences in fluoride exposure between boys and girls that warrant further exploration. It is also consistent with our prior study which showed that each $1 \mathrm{mg} / \mathrm{L}$ increase in water fluoride concentration was associated with a $0.57 \mathrm{mg} / \mathrm{L}$ increase in urinary fluoride among pregnant women in Canada [9]. Water fluoride thus appears to be a major source of fluoride exposure for both pregnant Canadian women and their children. Interestingly, mean urinary fluoride levels among children were very similar to those of their mothers (averaged across pregnancy) in both fluoridated (child: $0.66 \mathrm{mg} / \mathrm{L}$; maternal: $0.71 \mathrm{mg} / \mathrm{L}$ ) and non-fluoridated (child: $0.42 \mathrm{mg} / \mathrm{L}$; maternal: $0.41 \mathrm{mg} / \mathrm{L}$ ) areas.

Understanding the magnitude, patterns and sources of fluoride exposure among children is important for understanding the potential risk for adverse effects, as well as identifying vulnerable populations.

Strengths of our study include assessment of various sources of fluoride and multiple covariates, large sample sizes, and adjusting for specific gravity to control for varying urinary dilution across both cohorts. This study also has some limitations. First, urinary fluoride concentrations were measured in spot samples and there can be intra-individual variability in urinary fluoride concentrations from daily behaviors that were not controlled in this study (e.g., use of fluoridated toothpaste and consumption of bottled water). Additionally, because fluoride has a relatively short half-life (approximately six hours) [40], urinary fluoride measurements reflect recent exposures. Second, we relied on the mothers' self-reported use of tap water to estimate child tap water exposure, and we excluded those that did not report drinking tap water as we did not have information on bottled water use. For measurements of water fluoride, water fluoride concentrations were measured at the water treatment plant rather than the tap. However, this is likely to be non-differential misclassification of exposure since we would not expect differences in drinking water reporting based on fluoridation status. Third, the FFQ utilized in this study for PROGRESS may not have adequately captured true dietary fluoride intake because FFQs can be subject to recall biases/forgetting and the FFQs used in this study did not measure added salt.

\section{Conclusions}

We found that urinary fluoride levels are comparable among children in Mexico City and fluoridated Canadian communities, even though their sources of fluoride exposure differ. Other factors, including age and sex may also influence exposure patterns. Community water fluoridation in Canada appears to be a major source of fluoride exposure among children. Further studies are needed to clarify whether higher CUF among older children reflects different sources of exposure and/or differences in toxicokinetics, as well as investigate potential health effects of early-life fluoride exposure.

Author Contributions: Conceptualization, R.G., A.J.M., C.T., A.C., B.L. and M.M.T.-R.; methodology, R.G., A.J.M., C.T., A.C., E.A.M.-M., P.A.; formal analysis, R.G., A.J.M., A.C.; investigation, A.C., R.O.W., M.M.T-R.; resources, C.T., R.O.W., M.M.T.-R.; data curation, A.J.M., C.T., A.C., R.O.W., M.M.T.-R.; writing-original draft preparation, R.G., A.J.M.; writing-review and editing, R.G., A.J.M., C.T., A.C., B.L., E.A.M.-M., P.A., M.M.T.-R.; visualization, R.G., A.J.M., C.T.; supervision, A.J.M., C.T., B.L.; project administration, A.J.M., C.T., B.L., R.O.W., M.M.T.-R.; funding acquisition, A.J.M., C.T., R.O.W. All authors have read and agreed to the published version of the manuscript. 
Funding: This research was funded by the National Institutes of Health (NIH)/National Institute of Environmental Health Science (NIEHS)(grant numbers: P30ES023515, R01ES014930, R01ES021357, R24ES028522, R21ES027044). The MIREC Study was supported by the Chemicals Management Plan at Health Canada, the Ontario Ministry of the Environment, and the Canadian Institutes for Health Research (grant \# MOP-81285).

Acknowledgments: Nicole Lupien, Stéphanie Bastien, and Romy-Leigh McMaster and the MIREC Study Coordinating Staff for their administrative support, as well as the MIREC study group of investigators and site investigators; Christine Buckley, Frank Lippert, and Prithvi Chandrappa for their analysis of urinary fluoride at the Indiana University School of Dentistry; and Maddy Blazer from York University for assisting with gathering the water fluoride values. The authors are also grateful to the staff affiliated with community water treatment plants who helped to provide water fluoride data for this study. We also gratefully acknowledge the MIREC and PROGRESS families and participants for their ongoing participation.

Conflicts of Interest: The authors have no conflicts of interest relevant to this article to disclose.

\section{Abbreviations}

MIREC $=$ Maternal-Infant Research on Environmental Chemicals; $C U F=$ child urinary fluoride; FFQ $=$ Food Frequency Questionnaire; PROGRESS = Programming Research in Obesity, Growth, Environment and Social Stress.

\section{References}

1. Marinho, V.C.C. Cochrane reviews of randomized trials of fluoride therapies for preventing dental caries. Eur. Arch. Paediatr. Dent. 2009, 10, 183-191. [CrossRef] [PubMed]

2. Public Health Capacity and Knowledge Management Unit, Quebec Region for the Office of the Chief Dental Officer of Canada, Public Health Agency of Canada. The State of Community Water Fluoridation (CWF) across Canada. 2017. Available online: https://www.canada.ca/en/services/health/publications/healthy-living/ community-water-fluoridation-across-canada-2017.html (accessed on 1 June 2020).

3. Community Water Fluoridation. Available online: https://www.cdc.gov/fluoridation/basics/index.htm (accessed on 10 September 2018).

4. United States Environmental Protection Agency. Fluoride: Exposure and Relative Source Contribution Analysis; United States Environmental Protection Agency: Washington, DC, USA, 2010.

5. Secretaría-de-Salud. Norma Oficial Mexicana Nom-040-Ssa1-1993. Sal Yodatada y Sal Fluorada; Ministry of Health: Mexico City, Mexico, 1995.

6. Nutrient Data Laboratory, Beltsville Human Nutrition Research Center, Agricultural Research Service. USDA National Fluoride Database of Selected Beverages and Foods Release 2; U.S. Department of Agriculture: Beltsville, MD, USA, 2005.

7. Zohoori, F.V.; Buzalaf, M.A.R.; Cardoso, C.A.B.; Olympio, K.P.K.; Levy, F.M.; Grizzo, L.T.; Mangueira, D.F.B.; Sampaio, F.C.; Maguire, A. Total fluoride intake and excretion in children up to 4 years of age living in fluoridated and non-fluoridated areas. Eur. J. Oral Sci. 2013, 121, 457-464. [CrossRef] [PubMed]

8. Das, K.; Mondal, N.K. Dental fluorosis and urinary fluoride concentration as a reflection of fluoride exposure and its impact on IQ level and BMI of children of Laxmisagar, Simlapal Block of Bankura District, W.B., India. Environ. Monit. Assess. 2016, 188, 218. [CrossRef] [PubMed]

9. Till, C.; Green, R.; Grundy, J.; Hornung, R.; Neufeld, R.; Martinez-Mier, E.A.; Ayotte, P.; Muckle, G.; Lanphear, B. Community water fluoridation and urinary fluoride concentrations in a national sample of pregnant women in Canada. Environ. Health Perspect. 2018, 126, 107001. [CrossRef]

10. Rango, T.; Vengosh, A.; Jeuland, M.; Tekle-Haimanot, R.; Weinthal, E.; Kravchenko, J.; Paul, C.; McCornick, P. Fluoride exposure from groundwater as reflected by urinary fluoride and children's dental fluorosis in the main ethiopian rift valley. Sci. Total Environ. 2014, 496, 188-197. [CrossRef] [PubMed]

11. Ahmed, I.; Rafique, T.; Hasan, S.K.; Khan, N.; Khan, M.H.; Usmani, T.H. Correlation of fluoride in drinking water with urine, blood plasma, and serum fluoride levels of people consuming high and low fluoride drinking water in Pakistan. Fluoride 2012, 45, 384-388.

12. Jain, R.B. Concentrations of fluoride in water and plasma for US children and adolescents: Data from NHANES 2013-2014. Environ. Toxicol. Pharmacol. 2017, 50, 20-31. [CrossRef]

13. McLaren, L. Fluoridation exposure status based on location of data collection in the Canadian health measures survey: Is it valid? J. Can. Dent. Assoc. 2016, 82, 1-7. 
14. Singh, B.; Gaur, S.; Garg, V.K. Fluoride in drinking water and human urine in Southern Haryana, India. J. Hazard. Mater. 2007, 144, 147-151. [CrossRef] [PubMed]

15. Barberio, A.M.; Quiñonez, C.; Hosein, F.S.; McLaren, L. Fluoride exposure and reported learning disability diagnosis among Canadian children: Implications for community water fluoridation. Can. J. Public Health 2017, 108, e229-e239. [CrossRef]

16. Kumar, S.; Lata, S.; Yadav, J.; Yadav, J.P. Relationship between water, urine and serum fluoride and fluorosis in school children of Jhajjar District, Haryana, India. Appl. Water Sci. 2017, 7, 3377-3384. [CrossRef]

17. Cantoral, A.; Luna-Villa, L.C.; Mantilla-Rodriguez, A.A.; Mercado, A.; Lippert, F.; Liu, Y.; Peterson, K.E.; Hu, H.; Téllez-Rojo, M.M.; Martinez-Mier, E.A. Fluoride content in foods and beverages from Mexico City markets and supermarkets. Food Nutr. Bull. 2019, 40, 514-531. [CrossRef] [PubMed]

18. Riddell, J.K.; Malin, A.; Flora, D.; McCague, H.; Till, C. Association of water fluoride and urinary fluoride concentrations with attention deficit hyperactivity disorder in Canadian youth. Environ. Int. 2019, 133, 105190. [CrossRef] [PubMed]

19. Till, C.; Green, R.; Lanphear, B. Association between maternal fluoride exposure and child IQ-Reply. JAMA Pediatr. 2020, 174, 216-217. [CrossRef]

20. Green, R.; Lanphear, B.; Hornung, R.; Flora, D.; Martinez-Mier, E.A.; Neufeld, R.; Ayotte, P.; Muckle, G.; Till, C. Fluoride exposure during fetal development and intellectual abilities in a Canadian birth cohort. JAMA Pediatr. 2019, 173, 940-948. [CrossRef]

21. Bashash, M.; Marchand, M.; Hu, H.; Till, C.; Martinez-Mier, E.A.; Sanchez, B.N.; Basu, N.; Peterson, K.E.; Green, R.; Schnaas, L.; et al. Prenatal fluoride exposure and attention deficit hyperactivity disorder (ADHD) symptoms in children at 6-12 years of age in Mexico City. Environ. Int. 2018, 121, 658-666. [CrossRef]

22. Bashash, M.; Thomas, D.; Hu, H.; Martinez-Mier, E.A.; Sanchez, B.N.; Basu, N.; Peterson, K.E.; Ettinger, A.S.; Wright, R.; Zhang, Z.; et al. Prenatal fluoride exposure and cognitive outcomes in children at 4 and 6-12 years of age in Mexico. Environ. Health Perspect. 2017, 125, 097017. [CrossRef]

23. National Toxicology Program (NTP). Draft NTP Monograph on the Systematic Review of Fluoride Exposure and Neurodevelopmental and Cognitive Health Effects; U.S. Department of Health and Human Services: Washington, DC, USA, 2019.

24. Farmus, L.; Till, C.; Green, R.; Hornung, R.; Martinez-Mier, E.A.; Ayotte, P.; Muckle, G.; Lanphear, B.; Flora, D. Critical windows of fluoride neurotoxicity in Canadian children. Environment 2020, in revision.

25. Broadbent, J.M.; Thomson, W.M.; Ramrakha, S.; Moffitt, T.E.; Zeng, J.; Foster Page, L.A.; Poulton, R. Community water fluoridation and intelligence: Prospective study in New Zealand. Am. J. Public Health 2015, 105, 72-76. [CrossRef]

26. Buzalaf, M.A.R.; Whitford, G.M. Fluoride intake, metabolism and toxicity. In Fluoride and the Oral Environment; Buzalaf, M.A.R., Ed.; Karger: Basel, Switzerland, 2011; Volume 22, pp. 20-36.

27. Villa, A.; Anabalon, M.; Zohouri, V.; Maguire, A.; Franco, A.M.; Rugg-Gunn, A. Relationships between fluoride intake, urinary fluoride excretion and fluoride retention in children and adults: An analysis of available data. Caries Res. 2010, 44, 60-68. [CrossRef]

28. Thornton-Evans, G.; Junger, M.L.; Lin, M.; Wei, L.; Espinoza, L.; Beltran-Aguilar, E. Use of toothpaste and toothbrushing patterns among children and adolescents-United States, 2013-2016. Morb. Mortal. Wkly. Rep. 2019, 68, 87-90. [CrossRef]

29. Health Canada. Second Report on Human Biomonitoring of Environmental Chemicals in Canada; Authority of the Minister of Health: Ottawa, ON, Canada, 2013.

30. Abduweli Uyghurturk, D.; Goin, D.E.; Martinez-Mier, E.A.; Woodruff, T.J.; DenBesten, P.K. Maternal and fetal exposures to fluoride during mid-gestation among pregnant women in Northern California. Environ. Health 2020, 19, 38. [CrossRef]

31. Ketley, C.E.; Cochran, J.A.; Holbrook, W.P.; Sanches, L.; Van Loveren, C.; Oila, A.M.; O'Mullane, D.M. Urinary fluoride excretion by preschool children in six European countries. Community Dent. Oral Epidemiol. 2004, 32, 62-68. [CrossRef]

32. Arbuckle, T.E.; Fraser, W.D.; Fisher, M.; Davis, K.; Liang, C.L.; Lupien, N.; Bastien, S.; Velez, M.P.; Von Dadelszen, P.; Hemmings, D.G.; et al. Cohort profile: The maternal-infant research on environmental chemicals research platform. Paediatr. Perinat. Epidemiol. 2013, 27, 415-425. [CrossRef] 
33. Braun, J.M.; Wright, R.J.; Just, A.C.; Power, M.C.; Tamayo y Ortiz, M.; Schnaas, L.; Hu, H.; Wright, R.O.; Tellez-Rojo, M.M. Relationships between lead biomarkers and diurnal salivary cortisol indices in pregnant women from Mexico City: A cross-sectional study. Environ. Health 2014, 13, 50. [CrossRef] [PubMed]

34. Burris, H.H.; Braun, J.M.; Byun, H.M.; Tarantini, L.; Mercado, A.; Wright, R.J.; Schnaas, L.; Baccarelli, A.A.; Wright, R.O.; Tellez-Rojo, M.M. Association between birth weight and DNA methylation of IGF2, glucocorticoid receptor and repetitive elements LINE-1 and Alu. Epigenomics 2013, 5, 271-281. [CrossRef] [PubMed]

35. Martínez-Mier, E.A.; Cury, J.A.; Heilman, J.R.; Katz, B.P.; Levy, S.M.; Li, Y.; Maguire, A.; Margineda, J.; O'Mullane, D.; Phantumvanit, P.; et al. Development of gold standard ion-selective electrode-based methods for fluoride analysis. Caries Res. 2011, 45, 3-12. [CrossRef] [PubMed]

36. Martínez-Mier, E.A.; Soto-Rojas, A.E.; Buckley, C.M.; Margineda, J.; Zero, D.T. Evaluation of the direct and diffusion methods for the determination of fluoride content in table salt. Community Dent. Health 2009, 26, 204-210.

37. Hauser, R.; Meeker, J.D.; Park, S.; Silva, M.J.; Calafat, A.M. Temporal variability of urinary phthalate metabolite levels in men of reproductive age. Environ. Health Perspect. 2004, 112, 1734-1740. [CrossRef]

38. Rodríguez-Ramírez, S.; Mundo-Rosas, V.; Jiménez-Aguilar, A.; Shamah-Levy, T. Methodology for the analysis of dietary data from the Mexican National Health and Nutrition Survey 2006. Salud Publ. Mex. 2009, 51, S523-S529. [CrossRef]

39. Health Canada. Guidelines for Canadian Drinking Water Quality: Guideline Technical Document_Fluoride; Water, Air and Climate Change Bureau, Healthy Environments and Consumer Safety Branch, Health Canada: Ottawa, ON, Canada, 2010.

40. Aylward, L.L.; Hays, S.M.; Vezina, A.; Deveau, M.; St-Amand, A.; Nong, A. Biomonitoring equivalents for interpretation of urinary fluoride. Regul. Toxicol. Pharmacol. 2015, 72, 158-167. [CrossRef]

41. Lakens, D. Equivalence tests: A practical primer for t tests, correlations, and meta-analyses. Soc. Psychol. Personal. Sci. 2017, 8, 355-362. [CrossRef]

42. Robinson, A. Package "Equivalence": Provides Tests and Graphics for Assessing Tests of Equivalence; CRAN: Melbourne, Australia, 2016.

43. Forte, F.D.S.; Moimaz, S.A.S.; Sampaio, F.C. Urinary fluoride excretion in children exposed to fluoride toothpaste and to different water fluoride levels in a tropical area of Brazil. Braz. Dent. J. 2008, 19, $214-218$. [CrossRef] [PubMed]

44. Marthaler, T.M. Salt fluoridation and oral health. Acta Med. Acad. 2013, 42, 140-155. [CrossRef]

Publisher's Note: MDPI stays neutral with regard to jurisdictional claims in published maps and institutional affiliations.

(C) 2020 by the authors. Licensee MDPI, Basel, Switzerland. This article is an open access article distributed under the terms and conditions of the Creative Commons Attribution (CC BY) license (http://creativecommons.org/licenses/by/4.0/). 